\title{
Sensitivity of Building Loss Estimates to Major Uncertain Variables
}

\author{
Keith A. Porter, ${ }^{\text {a) }}$ M.EERI, James L. Beck, ${ }^{\text {b) }}$ M.EERI, and Rustem V. \\ Shaikhutdinov ${ }^{\text {c) }}$
}

This paper examines the question of which sources of uncertainty most strongly affect the repair cost of a building in a future earthquake. Uncertainties examined here include spectral acceleration, ground-motion details, mass, damping, structural force-deformation behavior, building-component fragility, contractor costs, and the contractor's overhead and profit. We measure the variation (or swing) of the repair cost when each basic input variable except one is taken at its median value, and the remaining variable is taken at its $10^{\text {th }}$ and at its $90^{\text {th }}$ percentile. We perform this study using a 1960 s highrise nonductile reinforced-concrete moment-frame building. Repair costs are estimated using the assembly-based vulnerability (ABV) method. We find that the top three contributors to uncertainty are assembly capacity (the structural response at which a component exceeds some damage state), shaking intensity (measured here in terms of damped elastic spectral acceleration, $S_{a}$ ), and details of the ground motion with a given $S_{a}$. [DOI: 10.1193/1.1516201]

\section{INTRODUCTION}

Uncertainty is generally costly in earthquake engineering. If one wants to ensure a minimum level of performance with a certain probability, then greater uncertainty in either seismic demand or capacity increases the level of nominal capacity that must be designed into the system. If one can reduce uncertainty, one can generally reduce cost. But there are many sources of uncertainty in earthquake engineering performance: shaking intensity, details of future ground motions with that intensity level, a variety of physical characteristics of the structure in question, construction and repair costs, and details of occupancy and use.

One can assess and possibly reduce uncertainties in each one, but which are the important ones deserving the most attention? By important variables, we mean the ones whose uncertainty contributes most strongly to overall uncertainty in seismic performance. There are two benefits to knowing the relative contribution of each variable to overall uncertainty in a performance metric. First, the variables that do not contribute much to overall uncertainty can reasonably be taken at their best-estimate value, rather

\footnotetext{
a) G. W. Housner Senior Research Fellow, California Institute of Technology, Pasadena, CA 91125-4400

b) Professor of Civil Engineering and Applied Mechanics, California Institute of Technology, Pasadena, CA 91125

c) Doctoral Candidate in Applied Mechanics, California Institute of Technology, Pasadena, CA 91125
}

\footnotetext{
Earthquake Spectra, Volume 18, No. 4, pages 719-743, November 2002; $₫$ 2002, Earthquake Engineering Research Institute
} 
than treated as random, thereby simplifying the analysis problem. Second, the variables that do contribute strongly to overall performance uncertainty can then be the focus of study to understand them better and perhaps reduce them.

This paper presents a study of future earthquake economic performance. It categorizes the variables that might contribute to overall performance uncertainty, and presents a simple methodology for evaluating their relative contribution. The methodology is illustrated using an engineered commercial building that has been the focus of a broader study by the authors on seismic vulnerability and real-estate investment decision making (Beck et al. 2002).

\section{SENSITIVITY TO A SET OF BASIC UNCERTAIN VARIABLES}

To determine the important uncertain variables of earthquake performance, we perform a deterministic sensitivity study that is sometimes employed in decision analysis. In decision analysis, a figure called a tornado diagram illustrates the sensitivity of an uncertain output value to the more-basic input variables that contribute to it. We assume here that the output is a known deterministic function of a variety of input variables, and that either the value or the probability distribution of each of the input variables is specified.

The output variable, as a deterministic function of one or more uncertain inputs, is studied using a series of deterministic tests. First, each input variable is set to its bestestimate value, and the output is measured. This establishes a baseline output. Then one input is set to an extreme value (a low or high value), and the output measured again. The input is then set to the other extreme, and the output is measured. The absolute value of the difference between the outputs from these two cases is a measure of the sensitivity of the output to that input variable. This difference is called the swing. The first input is then set to its best-estimate value, and the process repeated for the next input, to determine the swing associated with the variability of that input. One can then rank the input variables according to their swing. A larger swing reflects a moreimportant input uncertainty.

\section{BASIC UNCERTAIN VARIABLES CONSIDERED HERE}

The basic variables that affect seismic performance depend on the performance metric of interest. We consider here the performance metric of repair cost given the occurrence of a future earthquake, and include the following basic input variables:

1. Ground motion intensity. This is not a reference to MMI, but to the general severity of shaking at a site, which might be measured in terms of PGA, $S_{a}$, Arias intensity, etc.

2. Details of ground motion. Many different acceleration time histories can have their amplitudes scaled to result in the same intensity. Because intensity measures are generally imperfect indicators of structural response, the detailed ground motion record is a source of performance uncertainty.

3. Building mass.

4. Viscous damping. 
5. Parameters of the force-deformation relationship for the structural elements.

6. Capacity of building assemblies to resist damage.

7. Contractor unit costs.

8. Contractor overhead and profit.

Other parameters may also significantly affect the loss. These include ground failure (e.g., liquefaction), post-earthquake demand-driven cost inflation (called demand surge), the repair method employed to repair a given type of damage, the choice of union versus nonunion labor to perform repairs, and post-earthquake code changes that might require additional strengthening beyond the restoration of the building to its pre-earthquake condition. As potentially important as these are, we exclude them from present consideration.

\section{ASSEMBLY-BASED VULNERABILITY}

It is convenient to study loss uncertainty using the assembly-based vulnerability $(\mathrm{ABV})$ method. $\mathrm{ABV}$ is a framework for estimating earthquake-related repair costs for a facility as a function of ground motion intensity. For an overview of $\mathrm{ABV}$, see Porter et al. (2001b). Briefly, ABV works as follows.

The building is conceptualized as a collection of standard assemblies, such as reinforced concrete beam-columns, wallboard partitions, windows, etc. Our assemblycategorization system is that of RS Means Corp. (1997), with the addition of a numerical code to reflect installation conditions or other features relevant to seismic performance. Use of this standard system simplifies communication with engineers and contractors about the nature, construction cost, damageability, and repair costs of assemblies.

A structural model is created for structural analysis. Mass, damping, and forcedeformation parameters are treated as uncertain (random) variables. One selects a ground-motion intensity of interest, and then selects or generates a ground-motion time history with the desired intensity. Intensity can be measured a variety of ways; so far we have parameterized intensity in terms of spectral acceleration. Using the ground-motion time history and structural model, a nonlinear time-history structural analysis is performed, and the peak structural responses (member forces, deformations, interstory drifts, floor accelerations, etc.) are recorded.

Each damageable assembly in the facility is associated with one or more fragility functions, which give the probability that the assembly will experience or exceed a particular damage state, given some relevant structural response to which it is subjected. Damage states are defined by the repairs required to restore the assembly to its undamaged condition. (A fragility function can be seen as equivalent to a probability distribution of the capacity of the assembly. Consider the probability that the assembly will be damaged when subjected to some measure $x$ of structural response. That probability is equivalent to the probability that the capacity of the assembly to resist that damage is less than $x$.)

For each damageable assembly in the facility, one compares the structural response to which that assembly is subjected with the assembly's capacity. If the response exceeds 
the capacity, the assembly is taken as damaged, otherwise, the damage state has not been reached. By performing this comparison for every damageable assembly in the facility, one creates a complete picture of the damage state of the entire facility, and knows the repair efforts required to restore the facility to its undamaged state.

Given the damage state for each assembly, one estimates the direct cost to repair each of these damages, adds contractor overhead and profit, and produces an estimate of total repair cost, denoted here by $C_{R}$. For each such analysis performed, the result is an $\left(S, C_{R}\right)$ data pair, where $S$ is the shaking intensity of interest.

Knowing the required repair efforts, one can also use standard constructionscheduling procedures to determine the loss-of-use duration, and hence the loss-of-use cost, $C_{U}$. Repair cost $C_{R}$ is often expressed as a fraction of facility replacement cost; the ratio is typically referred to as the damage factor, denoted here by $D F$. Likewise, lossof-use $\operatorname{cost} C_{U}$ can be normalized by some income value such as rental income during a 12-month period.

One can repeat this process many times for many levels of shaking severity, and account for uncertainties in the basic random variables (mass, damping, etc.) via simulation or other reliability methods. The results are probability distributions of repair and loss-of-use costs as functions of shaking severity $S$. (The present study examines only repair costs).

A wide variety of facilities can be studied in this way. To date, the authors have examined hypothetical and real buildings whose structural systems include steel momentresisting frames, reinforced-concrete moment frames, and wood frames. For a detailed discussion, see Beck et al. (1999), Porter and Kiremidjian (2001), or Porter et al. (2001a). These and other studies have focused on developing probabilistic relationships between loss and shaking intensity for a variety of structures, but have not yet examined the contribution of each basic uncertain variable to the overall uncertainty in loss, to the degree addressed here.

One can treat all the basic variables such as shaking intensity, mass, damping, etc. as uncertain, and simulate them simultaneously, as was done in earlier ABV studies. In the present analysis, we treat each variable as uncertain, but control the simulation so that all the variables except one are taken at their median $\left(50^{\text {th }}\right.$ percentile $)$ value. The remaining variable is taken at a lower-bound value (its $10^{\text {th }}$ percentile), and the repair cost is calculated. It is then taken at an upper-bound value (its $90^{\text {th }}$ percentile), and the repair cost is again calculated. The difference between the two repair costs indicates how important uncertainty in the basic random variable is to total repair cost. The process is repeated for the other basic variables in turn, varying only one at a time between its $10^{\text {th }}$ and $90^{\text {th }}$ percentile values. The repair cost when all the variables are taken at their median value provides a baseline.

Whether one allows all the parameters to vary simultaneously or only one at a time, it is necessary to understand just how uncertain each one is. We therefore turn now to consideration of these basic variables. 


\section{CHARACTERIZING UNCERTAINTY IN SHAKING INTENSITY}

A variety of ground-motion intensity measures are available. Historically, Modified Mercalli Intensity has been used as a predictor of loss (e.g., ATC 1985), as well as instrumental measures such as peak ground acceleration or the spectral response measures: $S_{a}, S_{\nu}$, or $S_{d}$. Other measures intended to predict building performance have been proposed, e.g., by Cordova et al. (2001) and Luco and Cornell (2001). Two criteria for selection of an intensity measure $(I M)$ suggest themselves. First, the $I M$ must strongly correlate with the performance variable of interest, such as damage factor $(D F$, the ratio of repair cost to replacement cost). Second, an $I M$ is primarily useful insofar as hazard information is available (i.e., information on the occurrence probability of an earthquake with a given $I M$ level). Of course, the greater the correlation of an $I M$ with the performance variable, the stronger the incentive to develop the hazard information.

The arguments for various $I M \mathrm{~s}$ are familiar: $S_{a}$ is proportional to the maximum seismic force in a linear elastic SDOF system subjected to an earthquake, and therefore should be related to maximum forces in a similar structure. Similarly, $S_{d}$ is proportional to the maximum deformation of a linear elastic SDOF system, and therefore should be related to the damage experienced by displacement-sensitive components. The spectral response parameters are essentially interchangeable for light damping, as they are related through $S_{a} \approx \omega S_{\nu} \approx \omega^{2} S_{d}$, where $\omega$ is the angular frequency. On the other hand, inelastic response spectral parameters offer the advantages of better reflecting demand on structures that exceed elastic response, through the added parameter of ductility demand.

Luco and Cornell (2001) argue that an IM that is selected should be both an efficient and sufficient predictor of damage; efficient in that it is highly correlated with damage, and sufficient in that, conditioned on the $I M$, damage is not significantly correlated with other parameters of ground motion, particularly magnitude and distance.

In the end, the case for one $I M$ over another will be made not solely on theoretical considerations, but also on the basis of accumulated evidence of how well it predicts damage for various structures. Since for present purposes we are interested in the variability of repair cost attributable to variability in shaking intensity, it is necessary to use an intensity measure for which occurrence probability is available. Currently, probabilistic seismic hazard information is most readily available for damped elastic spectral acceleration response, $S_{a}$, which we therefore use for convenience. (More precisely, we use the $S_{a}$ for $5 \%$ viscous damping at the small-amplitude fundamental period of the building.)

If one assumes Poisson arrivals of earthquakes, the frequency form of the spectralacceleration hazard function $\left[G\left(S_{a}\right)\right.$, the annual frequency of events exceeding seismic shaking intensity $S_{a}$ ] can be used to determine the $S_{a}$ corresponding to a given nonexceedance probability, $P_{0}$, during a period, $t$, as follows. The number of earthquakes, $Y$, whose shaking exceeds $S_{a}$ in period $t$ is distributed according to the Poisson distribution:

$$
P[Y=y]=(\nu t)^{y} e^{-\nu t} / y !
$$

where $\nu=G\left(S_{a}\right)$ is the frequency of occurrences per unit time of events exceeding $S_{a}$. Thus, the probability that no earthquakes will occur $(Y=0)$ with shaking exceeding $S_{a}$ in time $t$ is given by 


$$
P[Y=0]=P_{0}=e^{-\nu t}
$$

One can solve for $\nu$ for a given non-exceedance probability $P_{0}$ and time $t$, and hence find the $S_{a}$ associated with this mean exceedance rate by inverting the hazard function $G$ :

$$
S_{a}=G^{-1}(\nu)=G^{-1}\left(-\ln \left(P_{0}\right) / t\right)
$$

In this study, we use $P_{0}=0.10,0.50$, and 0.90 for $t=50$ years, i.e., the $10^{\text {th }}, 50^{\text {th }}$, and $90^{\text {th }}$ percentiles for $S_{a}$.

\section{SELECTING RECORDINGS FOR USE IN THE SENSITIVITY STUDY}

Ground-motion characteristics other than the primary intensity measure $S_{a}$ undoubtedly affect the repair costs, but the question remains of how to parameterize these characteristics. A digital ground motion recording can have tens of thousands of data points, rather than one parameter. Two choices present themselves. First, one can perform a large number of loss analyses for a building of interest, each time using a different ground motion scaled to the intensity of interest. The lower-bound event can be selected as the one that produces the loss closest to some predetermined lower fractile such as the $10^{\text {th }}$ percentile. Likewise, the best-estimate and upper-bound events would be those producing the median and perhaps $90^{\text {th }}$ percentile loss. This approach is simple and provides some information about the degree of effect of detailed ground motion on loss, but offers no insight into why ground motions with equal intensity produce different performance.

A second alternative is to select a secondary intensity measure that is not highly correlated with the primary measure, but that might hypothetically strongly affect loss. From a large sample set of ground-motion recordings scaled to the desired primary intensity measure, one can select lower-bound, best-estimate, and upper-bound ground motions based on this secondary measure. Intensity measures worthy of examination include one recently proposed by Cordova et al. (2001), Arias intensity, and others. In order to pursue this approach, it would be necessary to determine the two-parameter hazard relationship. For example, one might know both $G\left(S_{a}\right)$ and have a probability distribution on the secondary intensity measure, conditioned on $S_{a}$. We hope to pursue this approach in later study, but for the limited purpose of demonstrating the swing associated with detailed ground motion, it is unnecessary. We therefore opt for the first, simpler approach.

\section{UNCERTAINTY IN MASS}

Building mass is an uncertain variable for several reasons: as-built member dimensions vary from those shown on the design documents; unit weights are imperfectly known; and actual building components can vary from those assumed in the design, e.g., layers of roofing are often added during the life of the building, which can significantly affect dead load. Ellingwood et al. (1980) summarize the conclusions of several authors, who feel that an adequate model for the probability distribution on dead load is the Gaussian distribution, with a mean value equal to the nominal (calculated) dead load, and a typical coefficient of variation of 0.10 . Thus, using the $10^{\text {th }}$ and $90^{\text {th }}$ percentiles of 
the Gaussian distribution as the lower and upper bounds of mass, one can take dead load as varying between $0.872 D_{n}$ and $1.128 D_{n}$, where $D_{n}$ refers to nominal dead load, and the factors 0.872 and 1.128 refer to the inverse of a Gaussian distribution with unit mean and coefficient of variation of 0.10 , evaluated at 0.10 and 0.90 , respectively.

\section{UNCERTAINTY IN VISCOUS DAMPING}

Some experimental data on the variability in viscous damping are available. McVerry (1979) presents results of system identification for 10 instrumented buildings that experienced strong motion in the 1971 San Fernando earthquake. These include five steel-frame buildings, four with reinforced-concrete frames, and one with reinforced concrete shearwalls. Two of these buildings experienced multiple earthquakes. McVerry (1979) finds that first-mode equivalent viscous damping ratios vary in single buildings between directional components and between earthquakes. Figure 1 shows his data plotted against peak ground acceleration. The figure shows that the damping ratio appears to be modestly sensitive to shaking intensity, implying that hysteretic damping contributes to the calculated equivalent viscous damping. Camelo et al. (2001) present similar results for several instrumented woodframe buildings subjected to strong motion or forced vibration; their data are shown in the right-hand plot of Figure 1. Note that McVerry (1979) parameterizes intensity via PGA, whereas Camelo et al. (2001) use $S_{a}$. Beck (1982) shows how the analytical method used to determine the equivalent viscous damping significantly affects the estimate of the damping ratio, implying additional uncertainty beyond that reflected in the scatter of the calculated damping ratios.

One can estimate uncertainty in "pure" viscous damping (i.e., aside from damping caused by hysteretic energy dissipation) by examining the scatter of the imputed viscous damping about a regression line at low levels of shaking intensity. Using the scatter about the regression line should correct to some degree for the mean effect of hysteretic damping, and restricting the analysis to low intensities should further limit the contribution to overall uncertainty from hysteretic damping. Results of a linear regression of these data (PGA $\leqslant 0.10 \mathrm{~g}$ in McVerry, 1979 , and $S_{a} \leqslant 0.10 \mathrm{~g}$ in Camelo et al., 2001) are shown in Table 1 . In the table, $\beta$ refers to the damping ratio, $\delta_{\beta}$ denotes the coefficient of variation for damping ratio, $R^{2}$ refers to the square of the correlation coefficient between acceleration $A$ (either PGA or $S_{a}$ ) and $\beta$, and $\delta_{\beta \mid A}$ refers to the coefficient of variation for damping, with the assumed mean effect of hysteretic damping removed via

$$
\delta_{\beta \mid A}=\delta_{\beta} \sqrt{1-R^{2}}
$$

An additional data point is provided by Taoko (1981), who presents damping ratios determined from forced-vibration tests for two high-rise steel-frame buildings in Japan, observing damping ratios for the first few modes to be in the range of $0.5 \%$ to $1.5 \%$. The average of the damping ratios is $1.1 \%$; the coefficient of variation, 0.3 . In light of these observations, it seems that a reasonable estimate of the coefficient of variation of the damping ratio is on the order of 0.3 to 0.4 . 

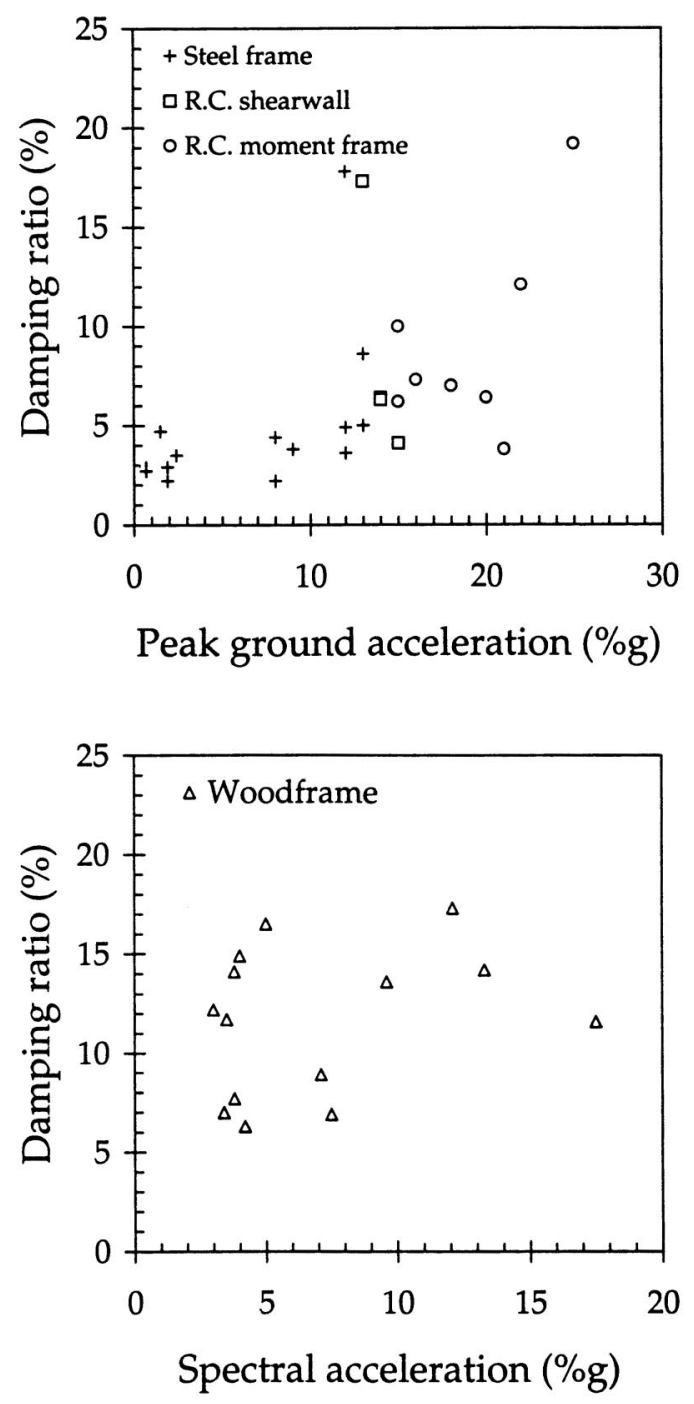

Figure 1. Equivalent viscous damping ratios identified by McVerry (1979), top, and Camelo et al. (2001), bottom. Within a structure type, damping ratio appears to be modestly sensitive to shaking intensity. Analysis of the data suggest a coefficient of variation for damping ratio of approximately 0.3 to 0.4 .

\section{UNCERTAINTY IN FORCE-DEFORMATION RELATIONSHIPS}

Uncertainty in the hysteretic behavior of structural elements results from a variety of sources: as-built members dimensions vary from construction documents, material properties differ from those assumed in the analysis, true stress-strain behavior at the element-fiber level differs from engineering idealizations, etc. How should one address these uncertainties as they affect the force-deformation relationships of the structural elements? The force-deformation relationships themselves can be quite complex. Ideali- 
Table 1. Uncertainty in damping ratio implied by system ID from strongmotion data

\begin{tabular}{ccc}
\hline \hline Parameter & McVerry (1979) & Camelo et al. (2001) \\
\hline$\sigma_{\beta}$ & $0.90 \%$ & $3.6 \%$ \\
$\mathrm{E}[\beta]$ & $3.3 \%$ & $11 \%$ \\
$\delta_{\beta}$ & 0.28 & 0.34 \\
$\mathrm{R}^{2}$ & 0.04 & 0.00 \\
$\delta_{\beta \mid \mathrm{A}}$ & 0.27 & 0.34 \\
\hline \hline
\end{tabular}

zations can involve a dozen or more potentially correlated parameters of which the designer has imperfect knowledge. An initial attempt to capture uncertainty in these parameters can be simple or complex. A simple approach would be to scale every force and deformation value on the force-deformation relationship by a single, random variable (let this approach be called random strength, constant stiffness). Slightly more complex would be to scale force values on the force-deformation relationship by one random variable, and deformation values by a second, correlated random variable (random strength and stiffness). One could also conceivably treat each parameter in the idealized hysteresis model as a random variable related through a covariance matrix. We reject this last approach for present purposes in order to concentrate on the general contribution of uncertainty in force-deformation to uncertainty in loss. The question then is, which of the two simpler approaches is reasonable?

Ellingwood et al. (1980) summarize research on variability in member resistance. For example, considering the resistance of reinforced-concrete flexural members, they suggest a coefficient of variation for flexural strength of 0.08 . They do not treat uncertainty in stiffness, which is also of interest here. Therefore, we performed a simple study of the moment-curvature relationship for a sample reinforced-concrete beam, $b=16$ in, $d=20$ in, three \#8 top bars, two \#8 bottom bars. We allowed $f_{c}^{\prime}$, concrete crushing strain $\varepsilon_{c}$, and steel yield stress $f_{y}$ to vary randomly: $\mathrm{E}\left[f_{c}^{\prime}\right]=8.3 \mathrm{ksi}, \delta\left[f_{c}^{\prime}\right]=0.18, \mathrm{E}\left[\varepsilon_{c}\right]$ $=0.0035, \delta\left[\varepsilon_{c}\right]=0.05, \mathrm{E}\left[f_{y}\right]=67.5 \mathrm{ksi}$, and $\delta\left[f_{y}\right]=0.098$, where $\mathrm{E}[\cdot]$ and $\delta[\cdot]$ refer to the expected value and coefficient of variation, respectively, of the variable inside the brackets. We then used UCFyber (ZEvent 2000) to find yield and ultimate moments and curvatures. After 20 simulations, we found a coefficient of variation for yield strength $\left(M_{y}\right)$ and yield curvature $\left(\phi_{y}\right)$ of 0.084 and 0.080 , respectively, with a high correlation coefficient $\left(\rho_{M y, \phi y}=0.96\right)$. We found coefficients of variation on ultimate strength $\left(M_{u}\right)$ and curvature at ultimate of 0.008 and 0.093 , respectively, with a correlation coefficient $\rho_{M u, \phi u}=0.76$. That this experiment produces an overall coefficient of variation for yield strength similar to that of Ellingwood et al. (1980), and high correlation between moment and curvature, argues for the random-strength, constant-stiffness approach. The random-strength, constant-stiffness model overstates by an order of magnitude the coefficient of variation for ultimate strength. Nonetheless, we find the random-strength, constant-stiffness model reasonably approximates the moment-curvature behavior of reinforced-concrete flexural members. 
In a later study (Beck et al. 2002), we also estimated uncertainty associated with imperfect modeling. That is, even if one knows exact member dimensions and material properties, an analytical model may imperfectly estimate the member force-deformation behavior. This modeling uncertainty adds modestly to overall uncertainty, but we do not reflect it here.

Another issue is how the hysteretic behavior of different elements is correlated. Perfect correlation would mean, for example, that if element $i$ were $20 \%$ stronger than nominal, so is element $j$. Perfect correlation would tend to produce greater uncertainty in overall structural response, and therefore represents a conservative approach. Zero correlation would mean that knowledge of the strength of element $i$ tells one nothing about element $j$. In this study, for simplicity and to be conservative regarding uncertainty, we assume perfect correlation.

The random-strength, constant-stiffness model also appears to be reasonable for steel moment-resisting frames. The elastic modulus $(E)$ and dimensions of rolled steel sections (and hence moment of inertia, $I$ ) have little uncertainty, and these parameters determine stiffness, whereas steel strength is less certain. Ellingwood et al. (1980) suggest coefficients of variation on resistance of steel structural members between 0.1 to 0.3 , somewhat greater than the strength uncertainty for reinforced concrete flexural members.

\section{UNCERTAINTY IN ASSEMBLY CAPACITY}

Assembly fragility is defined as the probability of an assembly exceeding some undesirable limit state (e.g., repairable damage to a building component such as a nonstructural partition) conditioned on some demand parameter (e.g., a structural response parameter such as interstory drift ratio). It is often conveniently modeled as a fragility function, which can be equated with a cumulative probability distribution whose random variable is the demand parameter. The larger the dispersion in the probability distribution, the greater the uncertainty in the threshold level of demand that leads to the specified damage. One can select lower-bound, best-estimate, and upper-bound values of assembly capacities by selecting a probability level corresponding to each, and inverting the fragility function at that probability level.

Given a probability distribution, it is straightforward to evaluate the $10^{\text {th }}, 50^{\text {th }}$, and $90^{\text {th }}$ percentiles of the demand-parameter distribution as the lower-bound, best-estimate, and upper-bound capacity of the assembly. It is common to use the lognormal distribution to describe the fragility of many assemblies. The $P$ fractile of the lognormal is given by

$$
X_{P}=x_{m} \exp \left(\beta \Phi^{-1}(P)\right)
$$

where $X_{P}$ is the demand parameter associated with probability $P$ that the assembly will be damaged, $\beta$ is the logarithmic standard deviation of the distribution, $\Phi^{-1}(P)$ is the inverse of the standard Gaussian distribution evaluated at $P$, and $x_{m}$ is the median of the distribution. The probability $P$ is taken as 0.1 for the $10^{\text {th }}$ percentile, 0.5 for the $50^{\text {th }}$, etc.

A variety of component fragility functions and their parameters are presented in 
Beck et al. (1999), Porter et al. (2001a), and Beck et al. (2002). These are developed using laboratory test data for most assemblies, and theoretical considerations (i.e., reliability methods) for the remainder.

\section{UNCERTAINTY IN CONTRACTOR COSTS}

Two types of costs are considered here: unit costs and contractor overhead and profit. By unit costs we mean the cost to restore a single unit of a damaged assembly to the undamaged state. Construction cost estimators typically compile construction cost estimates by describing the work to be performed in terms of a standard taxonomic system, often by the Uniformat system (ASTM 1996). The work to be performed is then measured in quantities of each taxonomic group. The cost for each task is calculated as the quantity of work times a cost per unit. The sum of the costs for the tasks is the direct cost; to this must be added indirect costs that are not attributable to tasks, such as administration, permits, mobilization, etc., and the contractor's profit. Together, overhead and profit tend to range between $15 \%$ and $20 \%$ of the direct cost, with larger jobs tending to have a lower factor for overhead and profit.

Unit cost estimates carry some degree of uncertainty, for various reasons: variability in costs of materials and of labor, uncertainty in the productivity of the workers, etc. With some exceptions, empirical data on the magnitude of this uncertainty are largely lacking. RS Means Corp. (1997), which performs extensive surveys of construction costs in the United States, recommends a cost contingency of $20 \%$ for the overall cost of a repair project, suggesting a coefficient of variation for total repair costs of approximately the same order of magnitude, perhaps 15 to $20 \%$. Alternatively, a construction cost estimator can determine the uncertainty in particular unit costs, based on his or her (unpublished) experience.

\section{DETERMINISTIC SENSITIVITY STUDY EXAMPLE: VAN NUYS HOTEL}

With this overview of the parameters of interest, their sources and magnitudes, we present a demonstration study of the sensitivity of loss to uncertainty in each basic random variable. This is a companion study to a full probabilistic ABV analysis of the same building, presented in Beck et al. (2002), which does not include a sensitivity analysis of the uncertainties.

\section{BUILDING DESCRIPTION}

The demonstration building is a seven-story, 66,000 $\mathrm{sf}\left(6,200 \mathrm{~m}^{2}\right)$ hotel located at 8244 Orion Ave., Van Nuys, CA, at $34.221^{\circ}$ north latitude, $118.471^{\circ}$ west longitude, in the San Fernando Valley of Los Angeles County, California. The location is shown in Figure 2. The building has been studied extensively, e.g., by Jennings (1971), Scholl et al. (1982), Islam (1996a, b), Islam et al. (1998), Li and Jirsa (1998), and Browning et al. (2000). To date, it appears that no researcher has assessed the seismic vulnerability of the building in terms of repair cost as a function of shaking intensity, or examined the effect of various uncertain variables on overall uncertainty in economic performance.

The hotel was designed by Rissman and Rissman Associates (1965) according to the 1964 Los Angeles City Building Code, and built in 1966. The lateral force-resisting sys- 


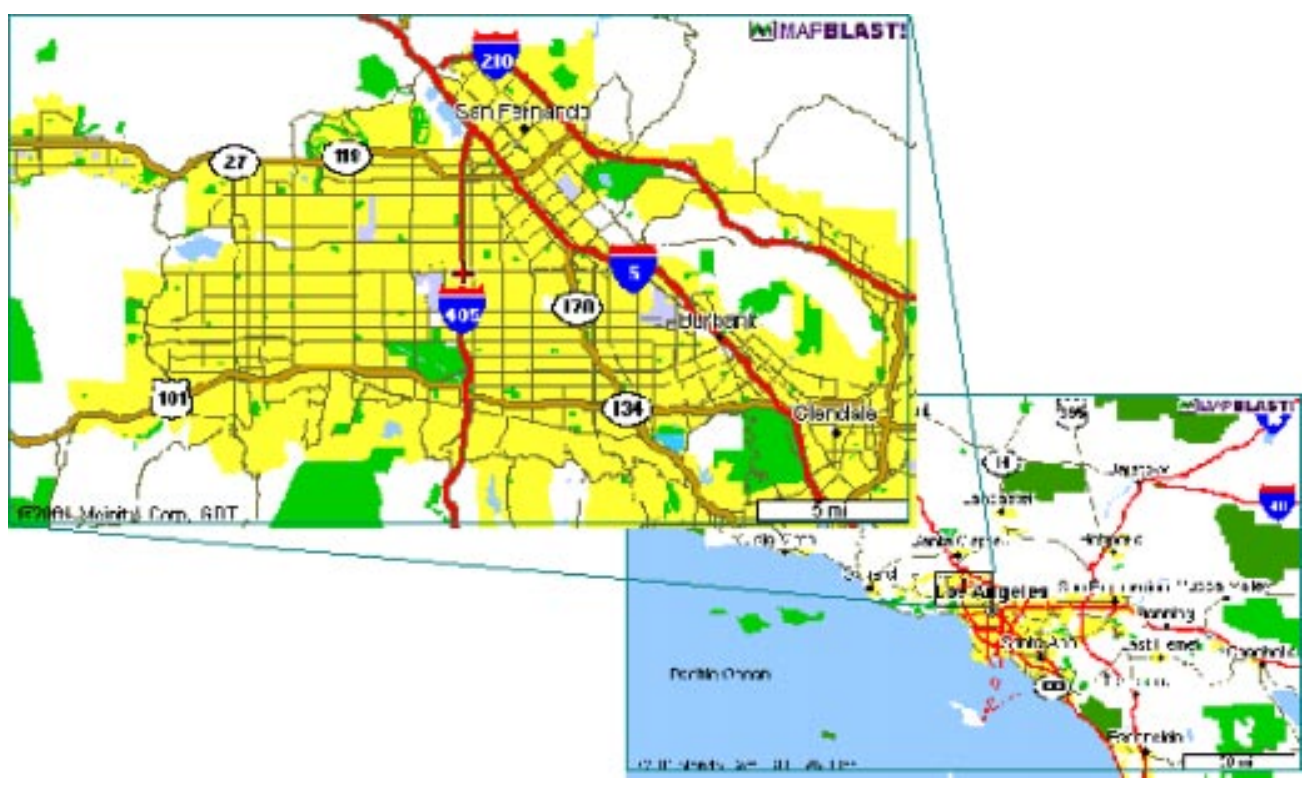

Figure 2. Location of the demonstration building. The hotel is located in the San Fernando Valley, northwest of downtown Los Angeles.

tem is a perimeter reinforced-concrete moment frame in both directions. The building was lightly damaged by the M6.6 1971 San Fernando event, approximately $20 \mathrm{~km}$ to the northeast, and severely damaged by the M6.7 1994 Northridge earthquake, whose epicenter was approximately $4.5 \mathrm{~km}$ to the southwest. After the 1994 earthquake, the building was retrofitted with new reinforced-concrete shearwalls, but we examine the build-

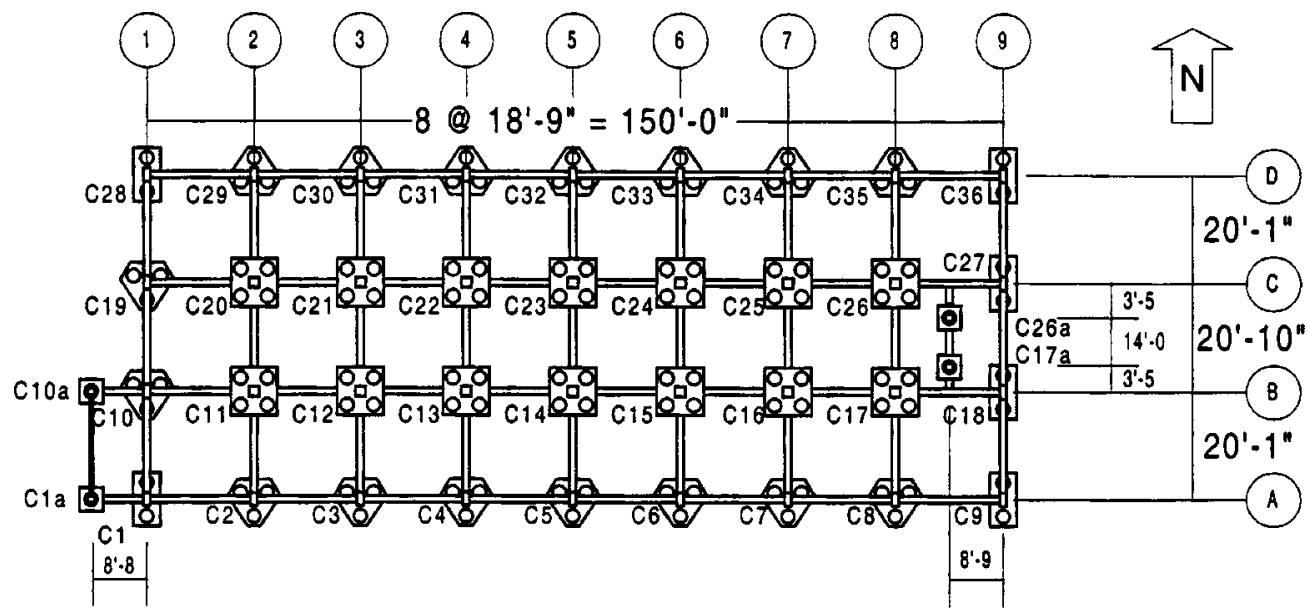

Figure 3. Column plan. The plan is regular, with three bays in the transverse direction, eight in the longitudinal direction. " $\mathrm{C} 1$ " through " $\mathrm{C} 36$ " refers to column numbers (designer's notation). 


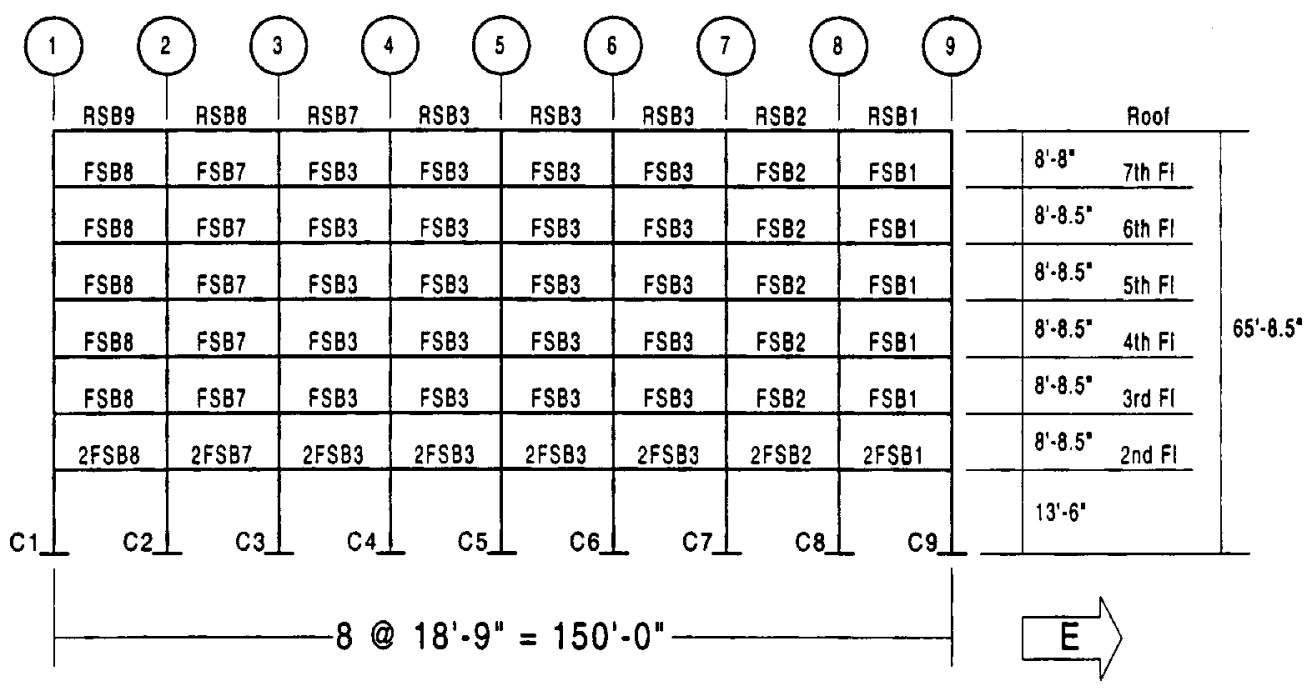

Figure 4. South frame elevation (omitting stair tower at west end), with designer's notation for beam and column numbering.

ing as it existed just before the earthquake. Floor plans, elevations, and column and beam reinforcement details and schedules can be found in Beck et al. (2002).

The column plan (with the designer's column numbers) is shown in Figure 3. In this analysis, the south frame is analyzed. The frame is regular in elevation, as shown in Figure 4. The figure shows the designer's notation for beam and column numbering. Columns in the south frame are 14 in wide by 20 in deep, i.e., oriented to bend in their weak direction when resisting lateral forces in the plane of the frame. Spandrel beams in the south frame are generally 16 in wide by 30 in deep at the second floor, 16 in wide by $22-1 / 2$ in deep at the third to seventh floors, and 16 in wide by 22 in deep at the roof.

Floor slabs are flat plates, 10 in thick at the second floor, 8-1/2 in at the third through seventh floors, and 8 in at the roof. The roof also has lightweight concrete topping of varying thickness (3-1/4 in to 8 in). The tops of the spandrel beams are flush with the top of the floor slab.

Column concrete has nominal strength of $f_{c}^{\prime}=5 \mathrm{ksi}$ for the first story, $4 \mathrm{ksi}$ for the second story, and $3 \mathrm{ksi}$ from the third story to the seventh. Beam and slab concrete is nominally $f_{c}^{\prime}=4 \mathrm{ksi}$ at the second floor and $3 \mathrm{ksi}$ from the third floor to the roof. Column reinforcement steel is scheduled as A432-62T (Grade 60) for billet bars. Beam and slab reinforcement is scheduled as ASTM A15-62T and A305-56T (Grade 40) for intermediate grade, deformed billet bars.

The ground floor, as it existed prior to the 1994 Northridge earthquake, contains a lobby, dining room, tavern, banquet room, and various hotel support services. Upper floors are arranged with 22 hotel suites accessed via a central corridor running the longitudinal axis of the building. The building is clad on the north and south facades with aluminum window wall, comprising 3/16-in heavy sheet glass in sliding frames, and 
1/4-in cement asbestos board panels with an ornamental sight-obscuring mesh of baked enamel or colored vinyl. Interior partitions are constructed of 5/8-in gypsum wallboard on 3-5/8-in metal studs at 16-in centers. Ceilings in the hotel suites in the second through seventh stories are a textured coating applied to the soffit of the concrete slab above; at the first floor and in the upper-story hallways, ceilings are suspended wallboard or lath and plaster. The east and west endwalls are finished on the inside with gypsum wallboard and on the outside with stucco.

Through-wall air-conditioning units are mounted in the waist panels below the windows and provide ventilation to the suites. Central HVAC is provided only for hallway and ground-floor spaces. Central HVAC equipment - fans, cooling towers, and packaged $\mathrm{AC}$ units - are located on the roof.

\section{SITE HAZARD AND GROUND-MOTION SELECTION}

Soil conditions at the site are found in Tinsley and Fumal (1985), who map surficial soil deposits in the Los Angeles region using a variety of sources. They describe the site soil as Holocene fine-grained sediment (silt and clay) with a mean shear-wave velocity of $200 \mathrm{~m} / \mathrm{sec}$ (and a standard deviation of $20 \mathrm{~m} / \mathrm{sec}$ ), corresponding to Site Class D, stiff soil, as defined by the International Code Council (2000), and Soil Profile Type $\mathrm{S}_{\mathrm{D}}$ according to the Structural Engineers Association of California (1999). California Geosystems (1994) performed four soil borings at the site, and report that site soils are "mostly brown silty fine sand and sandy silts with some clay binder. The composition of soils is fairly consistent." While soil densification during an earthquake is possible, the geotechnical engineers do not find liquefaction, lateral spreading, or other ground failures to be significant perils. In his study of the same building, Islam (1996b) reaches the conclusion that the "site coefficient factor [is] S2 or greater."

The hazard for the latitude and longitude of the site is drawn from Frankel and Leyendecker (2001), who provide mean annual exceedance frequency versus $S_{a}$ for periods of $1 \mathrm{sec}$ and $2 \mathrm{sec}$. Their hazard curves assume soil at the boundary of Classes B and C. Linearly interpolating between the two hazard curves for $\mathrm{T}=1.5 \mathrm{sec}$, and adjusting for the site soil conditions (Class D) using the site coefficient $F_{V}$ from the International Code Council (2000), one obtains the mean site hazard shown in Figure 5.

We select as the lower-bound, median, and upper-bound shaking intensity the $S_{a}$ with nonexceedance probabilities of $P_{0}=10 \%, 50 \%$, and $90 \%$ in $t=50$ years, respectively. The first $S_{a}$ represents an earthquake that the building is highly likely to experience in the next 50 years $(10 \%$ chance of nonexceedance $=90 \%$ chance of exceedance). The last two represent events that might typically be used to test immediate-occupancy and lifesafety performance objectives, respectively, for new design. Applying Equation 3 leads to the lower-bound, median, and upper-bound shaking intensities of $S_{a}=0.11,0.27$, and $0.58 \mathrm{~g}$. In fact, this building has already seen more than its fair share of earthquakes: the 1971 and 1994 earthquakes both shook it more strongly than the median event examined here.

Given the desired levels of $S_{a}$, we next select scaled ground motions to represent the $10^{\text {th }} 50^{\text {th }}$, and $90^{\text {th }}$ percentile ground-motion time histories. To make this selection, 20 ground motions are selected at random from set of 100 available records (Somerville 


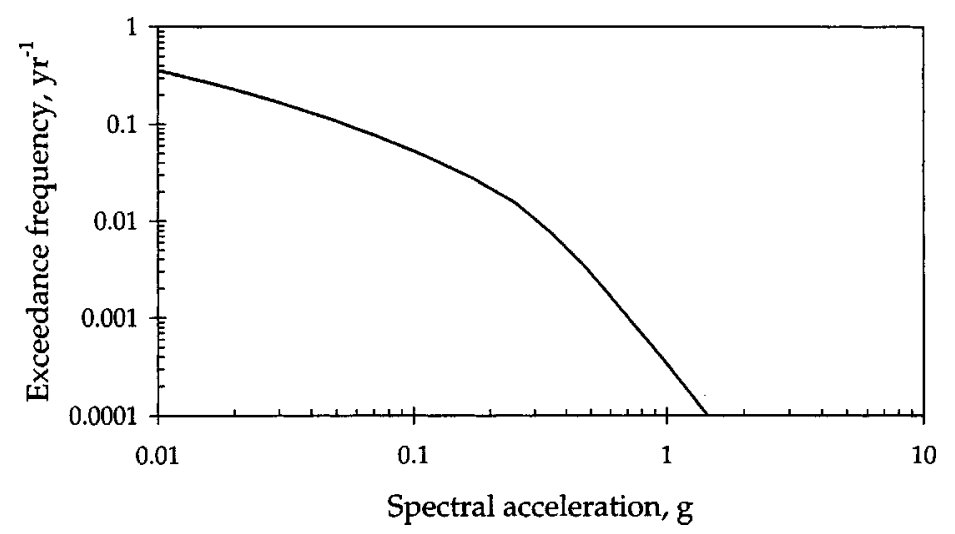

Figure 5. Site hazard. The figure gives the mean annual exceedance frequency of damped elastic spectral acceleration $S_{a}$ at the site, based on soil type D and $1.5 \mathrm{sec}$ period.

et al. 1997). The selection is made so that each record need be scaled in amplitude no more than $\pm 50 \%$ to have $S_{a}=0.27 \mathrm{~g}$ (50\% in 50-yr shaking). An ABV loss analysis is then performed with each scaled record, using the best-estimate values of structural characteristics, assembly capacity, unit costs, and overhead and profit.

Table 2. Recordings considered for representing lower-bound, median, and upper-bound ground-motion time histories

\begin{tabular}{lccccccc}
\hline \hline Record & $M$ & $R(\mathrm{~km})$ & $S_{a}, \mathrm{~g}$ & Scaling & $D F$ & $D F$ rank & Percentile \\
\hline LA51 & 6.1 & 3.7 & 0.44 & 0.61 & 0.45 & 1 & \\
LA49 & 6.2 & 15 & 0.34 & 0.79 & 0.36 & 2 & $90^{\text {th }}$ \\
LA59 & 6.0 & 17 & 0.19 & 1.41 & 0.35 & 3 & \\
LA47 & 7.3 & 64 & 0.32 & 0.85 & 0.30 & 4 & \\
LA01 & 6.9 & 10 & 0.19 & 1.44 & 0.29 & 5 & \\
NF02 & 7.4 & 1.2 & 0.17 & 1.61 & 0.28 & 6 & \\
LA55 & 6.0 & 9.6 & 0.32 & 0.85 & 0.26 & 7 & \\
LA56 & 6.0 & 9.6 & 0.40 & 0.68 & 0.26 & 8 & \\
LA02 & 6.9 & 10 & 0.20 & 1.36 & 0.26 & 9 & $50^{\text {th }}$ \\
LA19 & 6.0 & 6.7 & 0.25 & 1.08 & 0.24 & 10 & \\
LA54 & 6.1 & 8.0 & 0.34 & 0.79 & 0.23 & 11 & \\
LA17 & 6.7 & 6.4 & 0.16 & 1.73 & 0.23 & 12 & \\
NF08 & 7.1 & 8.5 & 0.15 & 1.77 & 0.22 & 13 & \\
LA08 & 7.3 & 36 & 0.21 & 1.28 & 0.22 & 14 & \\
LA07 & 7.3 & 36 & 0.23 & 1.20 & 0.21 & 15 & \\
LA50 & 6.2 & 15 & 0.34 & 0.78 & 0.21 & 16 & \\
LA53 & 6.1 & 8.0 & 0.42 & 0.65 & 0.20 & 17 & \\
LA46 & 7.7 & 107 & 0.38 & 0.71 & 0.16 & 18 & \\
LA45 & 7.7 & 107 & 0.30 & 0.91 & 0.14 & 19 & $10^{\text {th }}$ \\
LA58 & 6.5 & 1.0 & 0.27 & 1.00 & 0.14 & 20 & \\
\hline \hline
\end{tabular}


Each analysis produces an $\left(S_{a}, D F\right)$ pair. Table 2 shows the ground-motion records used, their $S_{a}$ as they appear in Somerville et al. (1997), and an amplitude scaling factor required to produce $S_{a}=0.27 \mathrm{~g}$. The table shows the calculated damage factor at $S_{a}$ $=0.27 \mathrm{~g}$, and the rank of the simulation by $D F$. We find that $\rho_{M, D F}^{2}=0.17$ and $\rho_{R, D F}^{2}$ $=0.16$, both of which are less than the $5 \%$ point for the equal-tails test of the hypothesis $\rho=0$, so one cannot reject the hypotheses that no linear relationship exists between either $M$ or $R$ and $D F$, satisfying the sufficiency test proposed by Luco and Cornell (2001) for this level of $S_{a}$.

Of the 20 records examined, LA45 produces the $10^{\text {th }}$-percentile $D F$, LA19 and LA54 produce the median values, and LA49, the $90^{\text {th }}$ percentile. Either LA19 or LA54 should be taken as the median, but in the analyses presented here, LA50 was erroneously used. Its damage factor is close to the median, so the associated error is likely modest.

\section{STRUCTURAL MODEL}

The building weighs approximately $134 \mathrm{psf}$, based on structural and architectural quantities and unit weights. This is mostly attributable to the 8-1/2-in normal-weight concrete slabs (106 psf) and the columns and spandrel beams (18 psf of deck). The balance (10 psf) is added to account for architectural finishes, and mechanical, electrical, and plumbing components. Bounding values for mass are based on a Gaussian distribution with a coefficient of variation of 0.10 . All masses are increased or decreased by the appropriate amount (i.e., masses are taken as perfectly correlated). Rayleigh damping is taken as $5 \%$ of critical with Gaussian distribution and coefficient of variation taken to be 0.40 .

The design information is used to create a model for structural analysis. The south frame, which was heavily damaged in the 1994 Northridge earthquake, is selected for modeling in a 2-D nonlinear time-history structural analysis. Material nonlinearities are considered, and geometric nonlinearities ignored. The moment-curvature and P-M interaction characteristics of the reinforced concrete members are assessed using UCFyber (ZEvent 2000). The cylinder strength of reinforced concrete is taken as the 28-day nominal value, plus 1.5 standard deviations ( $\sigma=600 \mathrm{psi}$ for $f_{c}^{\prime} \geqslant 4 \mathrm{ksi}$ ) to account for initial overstrength, plus an additional $69 \%$ to account for concrete age $(+30 \%)$ and earthquake strain rate $(+30 \%)$.

The flexural behavior of the beams and columns is represented by a one-component Giberson beam with plastic hinges at the ends (Sharpe 1974). The shear deformation for the beams is assumed to be elastic and is incorporated in the flexural elements. The shear deformation for the columns is modeled by inelastic springs attached to the ends of the flexural elements. Centerline dimensions are used with rigid-block offsets to account for joint stiffness.

Two hysteresis rules are used to model reinforced-concrete members' nonlinear behavior: the SINA trilinear hysteresis rule (Saiidi and Sozen 1979) is used to model stiffness degradation of reinforced concrete members in flexure; the Q-HYST bilinear hysteresis rule (Saiidi and Sozen 1979) is used to model the stiffness degradation of 
reinforced concrete members in shear. Strength degradation using Pincheira et al. (1999) is applied to both hysteretic rules. The structural analyses are performed using Ruaumoko (Carr 2001).

\section{ASSEMBLY CAPACITY AND REPAIR COSTS}

Assembly fragility functions and repair costs have been developed for all of the damageable assemblies in the building (see Porter and Kiremidjian 2001, Beck et al. 1999, and Beck et al. 2002) using laboratory test data for reinforced concrete beam-columns, drywall, and stucco partitions. Window fragility is based on theoretical considerations for window glazing by comparing theoretical glass strain as a function of drift angle with observed glass fracture strain.

As the application of these fragility functions may be unfamiliar to the reader, it is worthwhile to summarize their use in an $\mathrm{ABV}$ analysis. For each assembly, let $N_{D}$ denote the number of possible damage states other than undamaged. Let each damage state be denoted by an integer that increases with increasing severity of damage. Thus, each assembly must be in one damage state $d \in\left\{0,1, \ldots N_{D}\right\}$, where $d=0$ denotes a state of no damage. For a lognormal fragility function, the probability that a particular assembly will reach or exceed a particular damage state $d$, conditioned on the structural response $z$ to which it is subjected, is

$$
P_{f}(d)=P[D \geqslant d \mid Z=z]=\Phi\left(\frac{\ln \left(z / x_{m}(d)\right)}{\beta(d)}\right)
$$

where $D$ is the uncertain damage state of a particular assembly, $d$ is a possible damage state of that assembly, $Z$ is the uncertain structural response to which the assembly is subjected, $z$ is the calculated response from a particular simulation, and $x_{m}$ and $\beta$ are parameters of the fragility function, defined for each assembly type and damage state $d$.

In a probabilistic loss analysis, damage is simulated for each assembly and each simulation as follows. The structural analysis produces the structural response $z$ to which the assembly is subjected. Equation 6 is evaluated for each possible damage state. A random sample $u$ is drawn from a uniform probability distribution over $[0,1]$; this value is compared with each failure probability $P_{f}(d)$ for $d=1,2, \ldots N_{D}$. The assembly is said to have reached or exceeded damage state $d$ if $u \leqslant P_{f}(d)$. The maximum damage state $d_{m}$ reached or exceeded is the final simulated damage state of the assembly. That is,

$$
d_{m}=\max d: u \leqslant P_{f}(d)
$$

Note that the probability that an assembly is in damage state $d$, denoted by $P[D$ $=d \mid Z=z]$, is equal to $1-P_{f}(1)$ for $d=0$ (the undamaged state), or $P_{f}(d)-P_{f}(d+1)$ for $1 \leqslant d<N_{D}$, or $P_{f}(d)$ for $d=N_{D}$ (the most severe damage state).

Fragility functions for assemblies in the demonstration building, derived in Beck et al. (2002), are summarized in Table 3. Repair costs, provided by a professional cost estimator, are summarized in Table 4. Contractor overhead and profit is taken as uniformly distributed between 0.15 and 0.20 times the total direct cost. Thus, the total repair cost is given by 
Table 3. Summary of assembly fragility parameters. For derivation details, see Beck et al. (2002)

\begin{tabular}{|c|c|c|c|c|c|c|}
\hline Assembly type & Description & $\mathrm{d}$ & Limit State & Resp & $x_{m}$ & $\beta$ \\
\hline 6.1 .510 .1202 .02 & $\begin{array}{l}\text { Stucco finish, } 7 / 8^{\prime \prime} \\
\text { on } 3-5 / 8^{\prime \prime} \text { mtl stud, } 16^{\prime \prime} \mathrm{OC}\end{array}$ & 1 & Cracking & PTD & 0.012 & 0.5 \\
\hline 6.1 .500 .0002 .01 & $\begin{array}{l}\text { Drywall finish, } 5 / 8 \text {-in. } 1 \text { side, } \\
\text { on metal stud, screws }\end{array}$ & 1 & Visible dmg & PTD & 0.0039 & 0.17 \\
\hline 6.1 .500 .0002 .01 & $\begin{array}{l}\text { Drywall finish, } 5 / 8 \text {-in., } 1 \text { side, } \\
\text { on metal stud, screws }\end{array}$ & 2 & Signif. dmg & PTD & 0.0085 & 0.23 \\
\hline 6.1 .500 .0001 .01 & $\begin{array}{l}\text { Drywall partition, } 5 / 8 \text {-in., } 1 \text { side, } \\
\text { on metal stud, screws }\end{array}$ & 1 & Visible dmg & PTD & 0.0039 & 0.17 \\
\hline 6.1 .500 .0001 .01 & $\begin{array}{l}\text { Drywall partition, } 5 / 8 \text {-in., } 1 \text { side, } \\
\text { on metal stud, screws }\end{array}$ & 2 & Signif. dmg & PTD & 0.0085 & 0.23 \\
\hline 3.5.180.1101.01 & Nonductile CIP RC column & 1 & Light & PADI & 0.080 & 1.36 \\
\hline 3.5 .180 .1101 .01 & Nonductile CIP RC column & 2 & Moderate & PADI & 0.31 & 0.89 \\
\hline 3.5.180.1101.01 & Nonductile CIP RC column & 3 & Severe & PADI & 0.71 & 0.8 \\
\hline 3.5 .180 .1101 .01 & Nonductile CIP RC column & 4 & Collapse & PADI & 1.28 & 0.74 \\
\hline 3.5.190.1102.01 & Nonductile CIP RC beam & 1 & Light & PADI & 0.080 & 1.36 \\
\hline 3.5.190.1102.01 & Nonductile CIP RC beam & 2 & Moderate & PADI & 0.32 & 0.89 \\
\hline 3.5.190.1102.01 & Nonductile CIP RC beam & 3 & Severe & PADI & 0.71 & 0.8 \\
\hline 3.5.190.1102.01 & Nonductile CIP RC beam & 4 & Collapse & PADI & 1.28 & 0.74 \\
\hline 4.7.110.6700.02 & $\begin{array}{l}\text { Window, Al frm, sliding, hvy } \\
\text { sheet glass, } 4^{\prime} \times 2^{\prime}-6^{\prime \prime} \times 3 / 16^{\prime \prime}\end{array}$ & 1 & Cracking & PTD & 0.023 & 0.28 \\
\hline
\end{tabular}

Resp=type of structural response used as excitation in the fragility function $\mathrm{PTD}=$ peak transient drift ratio

PADI = Modified Park-Ang damage index (displacement portion): $\left(\phi_{m}-\phi_{y}\right) /\left(\phi_{u}-\phi_{y}\right)$, where $\phi_{m}=$ maximum curvature, $\phi_{y}=$ yield curvature, $\phi_{u}=$ curvature at maximum moment for the element in question, considering the element's own material and geometric properties

$x_{m}=$ median capacity; $\beta=$ logarithmic standard deviation of capacity

$$
C_{R}=\left(1+C_{O \& P}\right)\left(\sum_{j=1}^{N_{J}} \sum_{d=1}^{N_{D, j}} C_{j, d} N_{j, d}\right)
$$

Economic performance is more often expressed in terms of damage factor, defined as the ratio of repair cost to replacement cost:

$$
D F=C_{R} / R C N
$$

where

$C_{R}=$ cost to repair the building

$C_{O \& P}=$ contractor overhead and profit, assumed to be uniformly distributed between 0.15 and 0.20 , per the cost estimator

$C_{j, d}=$ cost to restore one unit of assembly type $j$ from damage state $d$

$D F=$ damage factor

$N_{D j}=$ number of possible damage states for assembly type $j$ 
Table 4. Summary of unit repair costs. The parameters $x_{m}$ and $\beta$ represent the median and logarithmic standard deviation of the cost to restore one unit of the assembly from damage state $d$ to the undamaged state. The nature of the repair is shown, and the units by which the assemblies are measured are shown in the column labeled "Unit." Unit costs are in dollars in 2001. For derivation details, see Beck et al. (2002).

\begin{tabular}{|c|c|c|c|c|c|c|}
\hline Assembly Type & Description & $d$ & Repair & Unit & $x_{m}$ & $\beta$ \\
\hline 6.1 .510 .1202 .02 & Stucco finish, $7 / 8^{\prime \prime}$, on $3-5 / 8^{\prime \prime} \mathrm{mtl}$ stud, $16^{\prime \prime} \mathrm{OC}$ & 1 & Patch & $64 \mathrm{sf}$ & 125 & 0.2 \\
\hline 6.1 .500 .0002 .01 & Drywall finish, 5/8-in., 1 side, on metal stud, screws & 1 & Patch & $64 \mathrm{sf}$ & 88 & 0.2 \\
\hline 6.1 .500 .0002 .01 & Drywall finish, 5/8-in., 1 side, on metal stud, screws & 2 & Replace & $64 \mathrm{sf}$ & 253 & 0.2 \\
\hline 6.1 .500 .0001 .01 & $\begin{array}{l}\text { Drywall partition, 5/8-in., } 1 \text { side, on metal stud, } \\
\text { screws }\end{array}$ & 1 & Patch & $64 \mathrm{sf}$ & 88 & 0.2 \\
\hline 6.1 .500 .0001 .01 & $\begin{array}{l}\text { Drywall partition, 5/8-in., } 1 \text { side, on metal stud, } \\
\text { screws }\end{array}$ & 2 & Replace & $64 \mathrm{sf}$ & 525 & 0.2 \\
\hline 3.5.180.1101.01 & N/D CIP R/C column & 1 & Epoxy & ea & 8000 & 0.42 \\
\hline 3.5.180.1101.01 & N/D CIP R/C column & 2 & Jacket & ea & 20500 & 0.4 \\
\hline 3.5.180.1101.01 & N/D CIP R/C column & 3,4 & Replace & ea & 34300 & 0.37 \\
\hline 3.5.190.1102.01 & N/D CIP R/C beam & 1 & Epoxy & ea & 8000 & 0.42 \\
\hline 3.5.190.1102.01 & N/D CIP R/C beam & 2 & Jacket & ea & 20500 & 0.4 \\
\hline 3.5.190.1102.01 & N/D CIP R/C beam & 3,4 & Replace & ea & 34300 & 0.37 \\
\hline 4.7.110.6700.02 & $\begin{array}{l}\text { Window, Al frame, sliding, hvy sheet glass, } 4^{\prime}-0 \\
\times 2^{\prime}-6^{\prime \prime} \times 3 / 16^{\prime \prime}\end{array}$ & 1 & Replace & ea & 180 & 0.2 \\
\hline 09910.700 .1400 & Paint on exterior stucco or concrete & 1 & Paint & sf & 1.45 & 0.2 \\
\hline 09910.920 .0840 & Paint on interior concrete, drywall, or plaster & 1 & Paint & sf & 1.52 & 0.2 \\
\hline
\end{tabular}

$N_{J}=$ number of damageable assembly types present in the building

$N_{j, d}=$ number of assemblies of type $j$ in damage state $d$

$$
R C N=\text { replacement cost (new) }
$$

To study the effect of uncertain capacity on overall loss uncertainty, we take all the capacity values at their $10^{\text {th }}, 50^{\text {th }}$, and $90^{\text {th }}$ percentiles, to represent lower-bound, bestestimate, and upper-bound assembly capacity, respectively. This is as opposed to allowing capacity to vary randomly in each assembly (per the normal, probabilistic ABV approach) or varying the capacity of each assembly type sequentially, e.g., varying only the capacity of reinforced concrete beam-columns, then only that of wallboard partitions, etc. The latter approach would be more informative of the effect of each individual assembly type, but would tend to emphasize the details rather than the general importance of assembly damageability.

Likewise, to study the effect of uncertainty in contractor costs, we take all the unitcost values at their $10^{\text {th }}, 50^{\text {th }}$, and $90^{\text {th }}$ percentiles simultaneously to represent lowerbound, best-estimate, and upper-bound of direct costs to the contractor. We employ mean values and uncertainties on unit costs provided by professional cost estimators (Young 2001, Machin 2001). In cases where the estimator judged the coefficient of variation for unit costs to be less than 0.20 , we applied 0.20 as a minimum value, in light of RS 
Table 5. Parameters of the sensitivity study

\begin{tabular}{lcccl}
\hline \hline Parameter & Lower-bound & Best-estimate & Upper-bound & Comment \\
\hline$S_{a}(\mathrm{~g})$ & 0.11 & 0.27 & 0.58 & Spectral acceleration \\
& (LA50,0.52) & (LA50,1.28) & (LA50, 2.74) & (Record, scaling factor) \\
Ground motion & LA45, 1.10 & LA50,1.28 & LA49, 1.26 & Record, scaling factor \\
Mass & $0.872 M_{n}$ & $M_{n}$ & $1.128 M_{n}$ & $M_{n}$ : nominal mass \\
Damping & $2.4 \%$ & $5.0 \%$ & $7.6 \%$ & Percent of critical \\
Force-deformation & 0.90 & 1.00 & 1.10 & Factor applied to $F \& d$ \\
multiplier & & & & in $F$ - $d$ relationships \\
Assembly capacity & $e^{\ln \left(x_{m}\right)-1.28 \beta}$ & $x_{m}$ & $e^{\ln \left(x_{m}\right)+1.28 \beta}$ & $x_{m}$ and $\beta$ from Table 3 \\
Costs: unit cost & $e^{\ln \left(x_{m}\right)-1.28 \beta}$ & $\chi_{m}$ & $e^{\ln \left(x_{m}\right)+1.28 \beta}$ & $x_{m}$ and $\beta$ from Table 4 \\
\multicolumn{1}{c}{ O\&P } & 0.15 & 0.175 & 0.20 & $C_{O \& P}$ of Equation 11 \\
\hline \hline
\end{tabular}

(Lower-bound, best-estimate, and upper-bound refer to the $10^{\text {th }}, 50^{\text {th }}$, and $90^{\text {th }}$ percentiles of the listed parameters, respectively)

Means Corp.'s (1997) cost contingency for repair. It would be highly desirable to collect empirical data on unit-cost uncertainty, in order to avoid this conscious and somewhat arbitrary application of judgment.

Finally, we take the lower-bound, median, and upper-bound values of $C_{O \& P}$ to determine the effect of uncertainty in the overhead and profit costs charged by the contractor.

\section{RESULTS}

Table 5 summarizes the input parameters used in the sensitivity study. Results of the sensitivity study are shown in Table 6 , and depicted graphically in the tornado diagram of Figure 6. The damage factor calculated here using best-estimate values of all parameters is $D F=0.21$, at $S_{a}=0.27 \mathrm{~g}$. This is approximately equal to the shaking intensity

Table 6. Summary of results. The table shows the damage factor (repair cost divided by replacement cost) that results when all parameters are set to their best-estimate value, except for one parameter, set to its low or high value. The table also shows the absolute difference ("swing") between the damage factors from the low and high values of the changed parameter.

\begin{tabular}{lccc}
\hline \hline & \multicolumn{3}{c}{ Damage factor (DF) } \\
\cline { 2 - 4 } Parameter $X$ & DF (low $X)$ & DF (high $X)$ & Swing \\
\hline Assembly capacity & 0.94 & 0.06 & 0.87 \\
Sa & 0.03 & 0.66 & 0.63 \\
Ground motion record & 0.14 & 0.36 & 0.22 \\
Unit cost & 0.13 & 0.33 & 0.20 \\
Damping & 0.29 & 0.15 & 0.14 \\
F-d multiplier & 0.23 & 0.17 & 0.07 \\
Mass & 0.20 & 0.22 & 0.02 \\
O\&P & 0.20 & 0.21 & 0.01 \\
\hline \hline
\end{tabular}




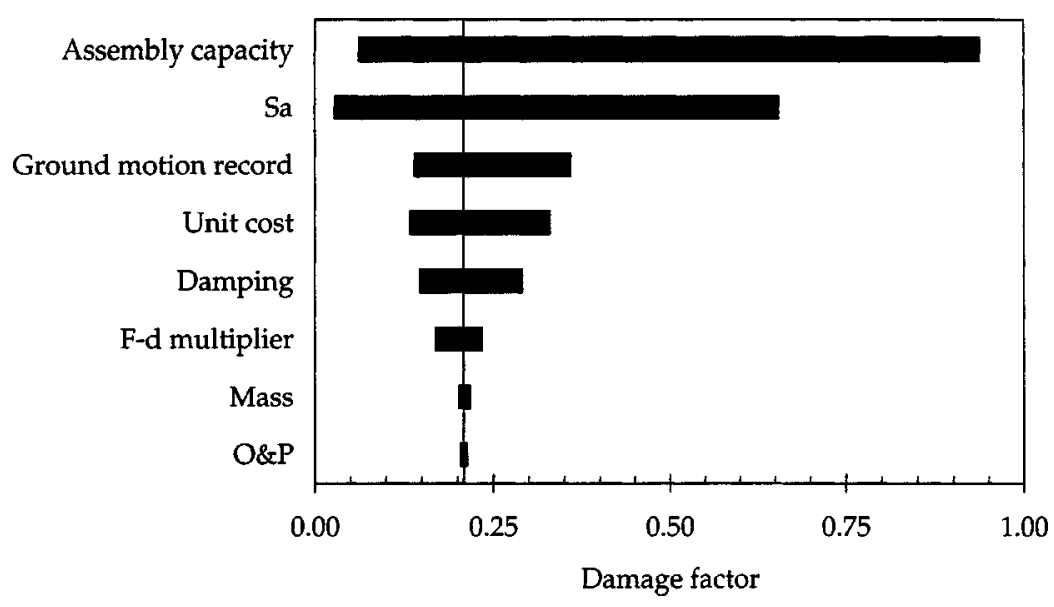

Figure 6. Results of the sensitivity study. The figure, called a tornado diagram, shows how the damage factor is affected by setting all input parameters to their best-estimate value except for one, which is set first to its low $\left(10^{\text {th }}\right.$ percentile $)$ and high $\left(90^{\text {th }}\right.$ percentile $)$ values. The resulting damage factors are represented by the ends of the horizontal bars. Parameters are shown in decreasing order of their effect on the damage factor. Thus, the parameter with the greatest impact on overall uncertainty is assembly capacity; the least important is the contractor's overhead and profit factor. The vertical line at $\mathrm{DF}=0.22$ gives the damage factor when all parameters are taken at their $50^{\text {th }}$-percentile values.

experienced by the building during the 1971 San Fernando earthquake $(0.34 \mathrm{~g})$, which resulted in a damage factor of approximately 0.11 , which is reasonably within the range of uncertainty reflected in Figure 6.

Figure 6 reflects only the seven-story nonductile reinforced concrete building structure in Van Nuys, but it offers some intriguing implications:

1. First, the greatest part of performance uncertainty is due to the uncertainty in the capacity of building assemblies to resist damage. This may be more readily reduced with additional knowledge than is the uncertainty in the shaking intensity of future earthquakes.

2. The figure suggests that uncertainty in the features that affect structural response (mass, damping, and the hysteretic behavior of the structural elements) are relatively minor contributors to overall performance uncertainty. That is, uncertainty in the structural analysis is significantly less important than uncertainty in the damage analysis. (By damage analysis we mean the portion of the performance analysis that estimates physical damage, given structural response.)

3. There is modest swing associated with the ground motion record after conditioning on $S_{a}$. This implies that $S_{a}$ alone is a fairly good intensity measure at the $50 \% / 50$-yr hazard level. The swing associated with the ground-motion record is 
comparable with that of the contractor's unit costs. This implies that a better intensity measure than $S_{a}$ could produce only a modest reduction in overall uncertainty.

Another data point is the study by Porter and Kiremidjian (2001) of a hypothetical pre-Northridge welded-steel moment-frame building. That study neglects uncertainties on structural characteristics, but it does produce a similarly large swing associated with the capacity of building components, most notably the capacity of pre-Northridge steel moment-frame connections.

\section{CONCLUSIONS}

This paper summarizes a deterministic sensitivity study for a high-rise nonductile reinforced concrete moment-frame building in Van Nuys, California. The study examines the sensitivity of the building's future economic performance (repair cost) to a number of basic uncertain variables, including shaking intensity, ground motion, structural characteristics, assembly damageability, and repair costs.

It finds that for the Van Nuys hotel building, the overall economic performancemeasured in terms of damage factor conditioned on the (uncertain) largest $S_{a}$ for the site in the next 50 years - is primarily sensitive to uncertainty in assembly capacity and shaking intensity (parameterized via spectral acceleration response at the building's small-amplitude fundamental period and 5\% damping). Loss is moderately sensitive to details of the ground motion (reflected in the variability of the repair cost for the bestestimate model, subjected to 20 different ground motions), and to the contractor's unit costs. Uncertainty associated with structural characteristics (mass, damping, and forcedeformation behavior) also have a modest effect on performance, although they individually account for less uncertainty than the contractor's unit repair costs.

If these results are duplicated for other buildings, this study offers several implications for practice and research:

- Interstory drift and other measures of structural response may be poor indicators of future economic performance if the majority of uncertainty in repair cost truly lies in the relationship between structural response and physical damage. Such drift limits are offered by FEMA 356 (FEMA 2000).

- Alternative measures of shaking intensity may not substantially reduce uncertainty in future repair cost. If it is not entirely clear to the reader why this is so, consider that the large $S_{a}$ swing reflects the general strength of shaking at the site, not the parameter we use to measure that shaking. The more-modest ground-motion record swing reflects the performance variability between records that have all been scaled to the same $S_{a}$. A better intensity measure than $S_{a}$ would only reduce this latter uncertainty. Site intensity would still vary substantially because of the potential for earthquakes of varying magnitudes and distances to affect the site, so a different way to measure the intensity could not affect that basic variability. 
- To reduce overall uncertainty in future repair cost, researchers should focus on new fragility models or additional mechanical testing to reduce uncertainty in assembly capacity.

Note that many potentially important uncertainties are not examined here. These include the correlation of assembly capacities between assemblies, the correlation between force-deformation behavior and component damageability, the use of union vs. nonunion labor; demand surge, building-code changes that would require additional strengthening beyond mere repair, the potential for the actual future repair method to differ from that assumed here, the potential that needed repairs will not be performed, and the possibility that preexisting damage will be imputed to the earthquake. Each of these topics is worthy of additional study. Note also that other potentially important losses such as loss-of-use cost are omitted from the present study.

\section{ACKNOWLEDGMENTS}

Portions of this research were funded by CUREE-Kajima Phase IV Joint Research Project. This work was also supported by the Earthquake Engineering Research Centers Program of the National Science Foundation under Award Number EEC-9701568. Both sources of support are gratefully acknowledged. Ray Young and John Machin of Ray Young \& Associates provided the unit-cost estimates as well as valuable advice regarding cost-estimation practice. Alice Rissman of Rissman and Rissman Associates provided copyrights to the architectural and structural drawings. Carlos Rocha of Rocha Nueze \& Associates met with the authors to discuss his seismic retrofit design for the demonstration building. The authors thank these individuals for their contribution.

\section{REFERENCES}

American Society for Testing and Materials (ASTM), 1996. E1557-96 Standard classification for building elements and related sitework-UNIFORMAT II, 1997 Annual Book of ASTM Standards, Section 4, Construction, Volume 04.11 Building Constructions, West Conshohocken, PA, 630-639.

Applied Technology Council (ATC), 1985. Earthquake Damage Evaluation Data for California, ATC-13, Redwood City, CA.

Beck, J. L., 1982. System identification applied to strong motion records from structures, Earthquake Ground Motion and its Effects on Structures, S. K. Datta, ed., American Society of Mechanical Engineers, New York, 109-134.

Beck, J. L., Kiremidjian, A., Wilkie, S., Mason, A., Salmon, T., Goltz, J., Olson, R., Workman, J., Irfanoglu, A., and Porter, K., 1999. Decision Support Tools for Earthquake Recovery of Businesses, Final Report, CUREe-Kajima Joint Research Program Phase III, Consortium of Universities for Earthquake Engineering Research, Richmond, CA.

Beck, J. L., Porter, K. A., Shaikhutdinov, R., Moroi, T., Tsukada, Y., and Masuda, M., 2002. Impact of Seismic Risk on Lifetime Property Values, Final Report, CUREE-Kajima Joint Research Program Phase IV, Consortium of Universities for Earthquake Engineering Research, Richmond, CA.

Browning, J., Li, Y., Lynn, A., and Moehle, J. P., 2000, Performance assessment for a reinforced concrete frame building, Earthquake Spectra 16 (3), 541-555. 
California Geosystems, 1994. Foundation Soils Investigation, Existing Holiday Inn Building, Roscoe Blvd and Orion Ave, Van Nuys, CA, Glendale, CA, 26 pp.

Camelo, V. S., Beck, J. L., and Hall, J. F., 2001. Dynamic Characteristics of Woodframe Structures, Consortium of Universities for Research in Earthquake Engineering, Richmond, CA, $68 \mathrm{pp}$.

Carr, A. J., 2001. Ruaumoko 2-D, University of Canterbury, Christchurch, New Zealand.

Cordova, P. P., Deierlein, G. G., Mehanny, S. S. F., and Cornell, C. A., 2001. Development of a two-parameter seismic intensity measure and probabilistic assessment procedure, 2nd U.S.Japan Workshop on Performance-Based Earthquake Engineering for Reinforced Concrete Building Structures 11-13 September 2000 in Sapporo, Japan, Pacific Earthquake Engineering Research Center, Richmond, CA.

Ellingwood, B., Galambos, T. V., MacGregor, J. G., and Cornell, C. A., 1980. Development of a Probability-Based Load Criterion for American National Standard A58, National Bureau of Standards, Washington, DC, $222 \mathrm{pp}$.

Federal Emergency Management Agency (FEMA), 2000. FEMA-356, Prestandard and Commentary for the Seismic Rehabilitation of Buildings, Washington, DC.

Frankel, A., and Leyendecker, E. V., 2001. Uniform Hazard Response Spectra and Seismic Hazard Curves for the United States, U.S. Geological Survey, Menlo Park, CA.

International Code Council, 2000. International Building Code 2000, International Conference of Building Officials, Whittier, CA, $756 \mathrm{pp}$.

Islam, M. S., 1996a. Analysis of the response of an instrumented 7-story nonductile concrete frame building damaged during the Northridge Earthquake, Proceedings of the 1996 Annual Meeting of the Los Angeles Tall Buildings Structural Council, May 10, 1996, Los Angeles, $C A$.

Islam, M. S., 1996b. Holiday Inn, 1994 Northridge Earthquake Buildings Case Study Project Proposition 122: Product 3.2, Seismic Safety Commission, Sacramento, CA, 189-233.

Islam, M. S., Gupta, M., and Kunnath, S., 1998. Critical review of the state-of-the-art analytical tools and acceptance criterion in light of observed response of an instrumented nonductile concrete frame building, Proceedings, Sixth U.S. National Conference on Earthquake Engineering, Seattle, Washington, May 31-June 4, 1998, Earthquake Engineering Research Institute, Oakland, CA, 11 pp.

Jennings, P. C., 1971. Engineering Features of the San Fernando Earthquake of February 9 , 1971, Report EERL 71-02, California Institute of Technology, Pasadena, CA.

Li, Y. R., and Jirsa, J. O., 1998, Nonlinear analyses of an instrumented structure damaged in the 1994 Northridge earthquake, Earthquake Spectra 14 (2), 245-264.

Luco, N., and Cornell, C. A., 2001. Structure-specific scalar intensity measures for near-source and ordinary earthquake ground motions, Earthquake Spectra (submitted for publication), http://pitch.stanford.edu/rmsweb/RMS_Papers/pdf/nico/EQ_Spectra01.pdf.

Machin, J., 2001. Personal communication.

McVerry, G. H., 1979. Frequency Domain Identification of Structural Models for Earthquake Records, Report No. EERL 79-02, California Institute of Technology, Pasadena, CA, http:// caltecheerl.library.caltech.edu/documents/disk0/00/00/02/23/00000223-00/7902.pdf, 221 pp.

Pincheira, J. A., Dotiwala, F. S., and D’Souza, J. T., 1999, Seismic analysis of older reinforced concrete columns, Earthquake Spectra 15 (2), 245-272.

Porter, K. A., Beck, J. L., Seligson, H. A., Scawthorn, C. R., Tobin, L. T., Young, R., and Boyd, T., 2001a. Improving Loss Estimation for Woodframe Buildings, Draft Final Report, Vol. 2, 
Consortium of Universities for Research in Earthquake Engineering, Richmond, CA, http:// www.curee.org/projects/woodframe_project/element4/task_4_1.html.

Porter, K. A., and Kiremidjian, A. S., 2001. Assembly-Based Vulnerability and Its Uses in Seismic Performance Evaluation and Risk-Management Decision-Making, John A. Blume Earthquake Engineering Center, Stanford, CA, $214 \mathrm{pp}$.

Porter, K. A., Kiremidjian, A. S., and LeGrue, J. S., 2001b, Assembly-based vulnerability of buildings and its use in performance evaluation, Earthquake Spectra 17 (2), 291-312.

Rissman and Rissman Associates, 1965. Holiday Inn Van Nuys Structural Drawings, Pacific Palisades, CA.

RS Means Corp., 1997. Means Assemblies Cost Data, Kingston, MA.

Saiidi, M., and Sozen, M. A., 1979. Simple and complex models for nonlinear seismic response of reinforced concrete structures, Report UILU-ENG-79-2031, Department of Civil Engineering, University of Illinois, Urbana, IL.

Scholl, R. E., Kustu, O., Perry, C. L., and Zanetti, J. M., 1982. Seismic Damage Assessment for High-Rise Buildings, URS/JAB 8020, URS/John A. Blume \& Associates, Engineers, San Francisco, CA, 321 pp.

Sharpe, R. D., 1974. The Nonlinear Response of Inelastic Structures, Ph.D. thesis, Department of Civil Engineering, University of Canterbury, Christchurch, New Zealand.

Somerville, P., Smith, N., Punyamurthula, S., and Sun, S., 1997. Development of Ground Motion Time Histories for Phase 2 of the FEMA/SAC Steel Project, SAC Joint Venture, Background Document Report No. SAC/BD-97/04.

Structural Engineers Association of California, 1999. Recommended Lateral Force Requirements and Commentary, $7^{\text {th }}$ Edition, Sacramento, CA, $440 \mathrm{pp}$.

Taoko, G. T., 1981. Damping measurements of tall structures, Proc. Second Specialty Conference on Dynamic Response of Structures: Experimentation, Observation, Prediction, and Control, January 15-16, 1981, Atlanta, GA, American Society of Civil Engineers, New York, NY, 308-322.

Tinsley, J. C., and Fumal, T. E., 1985. Mapping Quaternary sedimentary deposits for areal variations in shaking response, Evaluating Earthquake Hazards in the Los Angeles Region-An Earth-Science Perspective, U.S. Geological Survey Professional Paper 1360, U.S. Government Printing Office, Washington DC, 101-126.

Young, R., 2001. Personal communication.

ZEvent, 2000. UCFyber Version 2.4.1, Berkeley, CA.

(Received February 25, 2002; accepted August 14, 2002) 